\title{
Akt/hypoxia-inducible factor-1 $\alpha$ signaling deficiency compromises skin wound healing in a type 1 diabetes mouse model
}

\author{
LIFENG JING ${ }^{1 *}$, SHUANG LI ${ }^{1 *}$ and ${\text { QIN } L^{2}}^{2}$ \\ ${ }^{1}$ Graduate School of Southern Medical University, Guangzhou, Guangdong 510515; ${ }^{2}$ Department of Plastic Surgery, \\ General Hospital of Guangzhou Military Command, Guangzhou, Guangdong 510010, P.R. China
}

Received December 30, 2014; Accepted February 17, 2015

DOI: $10.3892 / \mathrm{etm} .2015 .2394$

\begin{abstract}
The aim of the present study was to investigate the mechanisms for impaired skin wound healing in subjects with diabetes. Type 1 diabetes (T1DM) was induced in BALB/c mice using streptozotocin. One month after the establishment of the T1DM mouse model, a wound was formed on the back of the mice, and tissues from the wounds and the margins were collected on days $0,3,7$ and 10. Protein levels of cluster of differentiation 31 (CD31) were detected using immunohistochemistry, and the mRNA levels of $A k t$, hypoxia-inducible factor-1 $\alpha(H i f-1 \alpha)$, vascular endothelial growth factor (Vegf), VEGF receptor 2 (Vegfr2), stromal cell-derived growth factor-1 $\alpha(S d f-1 \alpha)$ and CXC chemokine receptor 4 ( $C x c r 4)$ were determined using reverse transcription-quantitative polymerase chain reaction analysis. The corresponding protein levels were determined using western blotting. The skin wound healing rate in the T1DM mice was significantly lower than that in the control mice, and the protein level of CD31 in the wounded skin of the T1DM mice was significantly decreased. Furthermore, the overall mRNA levels of Akt, Hif-1 $\alpha$, Vegf, Vegfr $2, S d f-1 \alpha$ and Cxcr4 in the T1DM mice were significantly lower than those in the control mice, and similar trends were observed in the protein levels. In conclusion, skin wound healing was impaired in the T1DM mice, and this may have been caused by a deficiency of Akt/HIF-1 $\alpha$ and downstream signaling, as well as delayed angiogenesis.
\end{abstract}

Correspondence to: Professor Qin Li, Department of Plastic Surgery, General Hospital of Guangzhou Military Command, 111 Liuhua Street, Guangzhou, Guangdong 510010, P.R. China E-mail: crystaljasmine0302@aliyun.com

*Contributed equally

Key words: Akt/hypoxia-inducible factor-1 $\alpha$ signaling, vascular endothelial growth factor, angiogenesis, skin wound healing, diabetes mellitus

\section{Introduction}

Diabetes mellitus is a chronic disease threatening the health of individuals worldwide (1). There are multiple, often serious, complications associated with diabetes mellitus, one of which is impaired healing, which can lead to a reduction in physical activity and, in certain cases, chronic wounds and limb amputation $(1,2)$. An imbalance between the pro- and anti-inflammatory mediators accentuates diabetic vascular complications and impedes proper wound healing (3). Other factors that contribute to deficient healing in patients with diabetes include altered host responses; attenuated antibacterial defenses; prolonged inflammation; changes in protease activity; insufficient cell production for rapid and robust healing; angiogenic disorders; decreased production of growth factors; inadequate extracellular matrix production; and changes in apoptosis (1-5).

Wound healing is a complex process involving inflammation, granulation tissue formation, the production of new structures and tissue remodeling (2). The process is dependent upon a series of interactions between a variety of cell types, cytokine mediators and the extracellular matrix (1). In order for wound healing to be successful, a sufficient number of cells must be generated to participate in the repair $(2,6,7)$. Processes that have a negative effect on the generation of an adequate cell number, such as inappropriately high levels of fibroblast apoptosis, may limit healing $(6,7)$.

Hypoxia-inducible factor (HIF)-1 is a master regulator of oxygen homeostasis and is comprised of HIF-1 $\alpha$, a finely regulated subunit, and HIF-1 $\beta$ (also known as ARNT), a ubiquitously expressed subunit (8). HIF-1 controls the expression of $~ 70$ genes involved in several aspects of cancer progression, including angiopoietin (Angpt), vascular endothelial growth factor (Vegf), VEGF receptor 2 (Vegfr2), stromal cell-derived growth factor-1 $\alpha(S d f-1 \alpha), \mathrm{CXC}$ chemokine receptor 4 (CXcr 4$)$ and platelet-derived growth factor $(P d g f)$. The expression of mRNAs encoding Vegf, Angpt1, Angpt2, Pdgf-B and placental growth factor is impaired in wounds of genetic diabetic mice (9). Previous studies have shown that impaired Hif- $1 \alpha$ and Vegf expression in the skin of limbs leads to decreased vascular vessel density, poor blood circulation and impaired wound healing, which are important causes of diabetic foot injury $(10,11)$. Although oxygen tension plays a major role in the control of HIF-1 stability, this factor can be further 
modulated by either transcriptional or post-transcriptional mechanisms activated by hormones, or growth-factor-dependent pathways, including the mitogen-activated protein kinase or phosphoinositide 3-kinase (PI3K) cascades (8). Few studies, however, have investigated the changes in Akt/HIF-1 signaling or the differences between normal and diabetic wounds throughout the healing process (12); therefore, the aim of the present study was to establish a mouse model of type 1 diabetes (T1DM) with skin wounds and to analyze the mRNA and protein changes in Akt, HIF-1 $\alpha$, VEGF, VEGFR2, SDF-1 $\alpha$ and CXCR4 in the healing process of normal and diabetic wounds, in order to investigate a possible association between Akt/HIF-1 $\alpha$ signaling and vascular vessel formation.

\section{Materials and methods}

Materials. Streptozotocin (STZ) was purchased from Sigma-Aldrich (St. Louis, MO, USA). A blood glucose meter and test strips were obtained from Johnson \& Johnson (New Brunswick, NJ, USA). TriPure isolation reagent, a reverse transcription (RT) kit and SYBR ${ }^{\circledR}$ Green I fluorescent dyes were purchased from Roche (Basel, Switzerland). Anti-Akt (cat. no. 4691P, rabbit, 1:1,000, monoclonal), anti-VEGFR2 (cat. no. 2479S, rabbit, 1:1,000, monoclonal), anti-SDF1 (cat. no. 3740S, rabbit, polyclonal) and anti-rabbit immunoglobulin G-horseradish peroxidase (cat. no. 7074S) antibodies were obtained from Cell Signaling Technology, Inc. (Beverly, MA, USA). Anti-cluster of differentiation 31 (CD31; cat. no. sc-1506, goat, polyclonal $\mathrm{IgG}, 1: 50$ ) antibody was purchased from Santa Cruz Biotechnology, Inc. (Dallas, TX, USA). Anti-HIF-1 $\alpha$ (cat. no. GTX30647, rabbit, polyclonal, 1:1,000) antibody was purchased from GeneTex, Inc. (Irvine, CA, USA). Anti-VEGF (cat. no. ABS82, rabbit, polyclonal, 1:1,000) and anti-CXCR4 (cat. no. AB1847. rabbit, polyclonal, 1:800) antibodies were obtained from EMD Millipore (Billerica, MA, USA). $\beta$-actin (cat. no. E021070-03) antibody was purchased from EarthOx Life Sciences (Millbrae, CA, USA). Diethyl pyrocarbonate was purchased from MP Biomedicals (Santa Ana, CA, USA).

Animals. Sixty 6-week-old BALB/c male $(\mathrm{n}=30)$ and female $(\mathrm{n}=30)$ mice $(20 \pm 2.0 \mathrm{~g})$ were provided by the Animal Center of the General Hospital of Guangzhou Military Command (Guangzhou, China). The mice were fed food and water ad libitum in plastic cages at $21 \pm 2^{\circ} \mathrm{C}$ and maintained on a 12 -h light/dark cycle with a relative humidity of $40-50 \%$. The mice were allowed to acclimate for one week prior to the study.

Establishment of a T1DM mouse model. The T1DM mouse model was established with STZ, as described previously (13). The mice were randomly divided into control and T1DM groups. The mice were fasted for 14-16 $\mathrm{h}$ with free access to water, and injected intraperitoneally with $1 \%$ STZ $(40 \mathrm{mg} / \mathrm{kg}$ ) in the T1DM group and an equal volume of citric acid buffer solution $(0.1 \mathrm{mmol} / 1, \mathrm{pH} 4.4)$ in the control group. The mice were injected once a day for 5 days and could access water and food freely following injection. Tail vein blood was collected to measure blood glucose levels using a blood glucose meter. The model was considered to be successful when random blood glucose levels were $>16.7 \mathrm{mmol} / \mathrm{l}$ (14).
Sample collection. Four weeks after the establishment of the T1DM mouse model, the animals were anesthetized with $1 \%$ chloral hydrate. Following the disinfection of the back, a portion of the skin (full thickness skin near the neck) with a 6-mm diameter was removed by a special puncher. No drugs were used to treat the wounds and the mice were fed individually. The full thickness skin of the wounds and the margins were collected on days $0,3,7$ and 10 after trauma, and immediately stored in liquid nitrogen for further study.

Calculation of wound healing rate. The wound area was calculated on days $0,3,7$ and 10 after the trauma. Images of the wounds were captured using a digital camera with a scale bar and the wound area was calculated with Image-Pro Plus software (version 6.0; Media Cybernetics, Inc., Rockville, MD, USA). The wound healing rate was calculated with the following formula: Wound healing rate $=[($ Initial wound healing area) - (wound healing area on day $\mathrm{N}$ )]/(initial wound healing area) $\mathrm{x} 100 \%$.

Immunohistochemistry. Paraffin sections $(5-\mu \mathrm{m})$ were generated from the wound and margin tissues. The sections were infused in xylene three times (10 $\mathrm{min} / \mathrm{time})$ and subjected to ethanol infusion $(90,75$ and $50 \%$, each for $3 \mathrm{~min}$ ) and double-distilled $\mathrm{H}_{2} \mathrm{O}$ (3 min). For the immunohistochemical staining, the sections were boiled in antigen restoration solution (cat. no. P0081; Beyotime Institute of Biotechnology, Haimen, China) for 3 min and cooled naturally. Following cooling, the sections were incubated with $3 \% \mathrm{H}_{2} \mathrm{O}_{2}$ at room temperature for $10 \mathrm{~min}$ and blotted with $3 \%$ horse serum for $1 \mathrm{~h}$. The sections were subsequently incubated with primary antibodies at $4^{\circ} \mathrm{C}$ overnight. All steps were performed in accordance with the instructions provided by the manufacturer of the GTVision ${ }^{\mathrm{TM}}$ III Detection System/Mo\&Rb (cat. no. GK500705; Gene Tech Co. Ltd., Shanghai, China). The nuclei were stained with hematoxylin and eosin.

$R T$-quantitative polymerase chain reaction $(q P C R)$. Total RNA was extracted from the tissues using TriPure reagent in accordance with the manufacturer's instructions (Roche). A total of $1 \mu \mathrm{g}$ total RNA was used for the RT reaction under the following conditions: $42^{\circ} \mathrm{C}$ for $20 \mathrm{~min}$ and $99^{\circ} \mathrm{C}$ for $5 \mathrm{~min}$. The level of gene expression was subsequently determined using SsoFast ${ }^{\mathrm{TM}}$ EvaGreen ${ }^{\circledR}$ Supermix (Bio-Rad, Hercules, CA, USA) on a CFX96 Touch ${ }^{\mathrm{TM}}$ Real-Time PCR Detection system (Bio-Rad) with the following cycle conditions: $94^{\circ} \mathrm{C}$ for $15 \mathrm{sec} ; 58^{\circ} \mathrm{C}$ for $30 \mathrm{sec}$; and $72^{\circ} \mathrm{C}$ for $30 \mathrm{sec}(40$ cycles). Target gene expression was normalized to that of $\beta$-actin. The primer sequences are listed in Table I. All primers were synthesized by Life Technologies (Guangzhou, China).

Western blotting. Wound and margin tissues were collected and washed twice with ice-cold phosphate-buffered saline. Following washing, the tissues were lysed in radioimmunoprecipitation assay lysis buffer (Beyotime, Wuhan, China), containing $50 \mathrm{mM}$ Tris (pH 7.4), $150 \mathrm{mM} \mathrm{NaCl}, 1 \%$ Triton X-100, $1 \%$ sodium deoxycholate, $0.1 \%$ sodium dodecyl sulfate (SDS), $1 \mathrm{mM}$ phenylmethylsulfonylfluoride, $0.15 \mathrm{U} / \mathrm{ml}$ aprotinin and $1 \mathrm{mg} / \mathrm{ml}$ pepstatin. Whole lysates were collected and the proteins were separated using SDS-PAGE and transferred 
Table I. Primer sequences.

\begin{tabular}{|c|c|}
\hline Genes & Primer sequences \\
\hline$H i f-1 \alpha$ & $\begin{array}{l}\text { Forward: 5'-ACCTTCATCGGAAACTCCAAAG-3' } \\
\text { Reverse: 5'-CTGTTAGGCTGGGAAAAGTTAGG-3 }\end{array}$ \\
\hline$A k t$ & $\begin{array}{l}\text { Forward: 5'-CCCTGCTCCTAGTCCACCA-3' } \\
\text { Reverse: 5'-ACATCTGCAAGTACGTTCGTT-3' }\end{array}$ \\
\hline Vegf & $\begin{array}{l}\text { Forward: 5'-CTTGTTCAGAGCGGAGAAAGC-3' } \\
\text { Reverse: 5'-ACATCTGCAAGTACGTTCGTT-3' }\end{array}$ \\
\hline Vegfr2 & $\begin{array}{l}\text { Forward: 5'-TGGGCAGTCAAGTCCGAATC-3' } \\
\text { Reverse: 5'-TTGGCGTAGACTGTGCATGT-3' }\end{array}$ \\
\hline$S d f-1 \alpha$ & $\begin{array}{l}\text { Forward: 5'-GAGAGCCACATCGCCAGAG-3' } \\
\text { Reverse: 5'-TTTCGGGTCAATGCACACTTG-3' }\end{array}$ \\
\hline Cxcr 4 & $\begin{array}{l}\text { Forward: 5'-AGCATGACGGACAAGTACC-3' } \\
\text { Reverse: 5'-GATGATATGGACAGCCTTACAC-3' }\end{array}$ \\
\hline$\beta$-actin & $\begin{array}{l}\text { Forward: 5'-GACAGGATGCAGAAGGAGAT-3' } \\
\text { Reverse: 5'-TTGCTGATCCACATCTGCTG-3' }\end{array}$ \\
\hline
\end{tabular}

Hif- $1 \alpha$, hypoxia-inducible factor-1 $\alpha$; Vegf, vascular endothelial growth factor; Vegfr2, VEGF receptor 2; $S d f-1 \alpha$, stromal cell-derived growth factor-1 $\alpha$; Cxcr4, CXC chemokine receptor 4.

onto polyvinylidene fluoride membranes. A blocking step was then performed using 5\% bovine serum albumin (Sigma-Aldrich) at room temperature for $1 \mathrm{~h}$, and the blots were incubated with primary antibody at $4^{\circ} \mathrm{C}$ overnight and with secondary antibody at room temperature for $1 \mathrm{~h}$. Following incubation, the blots were washed extensively, developed using a chemiluminescent assay kit (Cell Signaling Technology, Inc.) and exposed to films (Kodak, Rochester, NY, USA) for the appropriate periods of time. The immunoblot band densities were quantified using ImageJ software (National Institutes of Health, Bethesda, MD, USA) and normalized with $\beta$-actin.

Ethics statement. The protocol for this study was reviewed and approved by the Ethics Committee of the General Hospital of Guangzhou Military Command. Animal welfare and experimental procedures were performed strictly in accordance with the Guide for the Care and Use of Laboratory Animals (The Ministry of Science and Technology of China, 2006) and the associated ethical regulations of the hospital. All efforts were made to minimize any animal suffering and to reduce the number of animals used.

Statistical analysis. Data are expressed as the mean \pm standard deviation and were analyzed using SPSS software (version 13.0; SPSS Inc., Chicago, IL, USA). A W test was used to evaluate normality within the group, and the Student's t-test was used to evaluate the difference between two groups. $\mathrm{P}<0.05$ was considered to indicate a statistically significant difference.

\section{Results}

Wound healing rate is decreased in T1DM mice. One month after the establishment of the T1DM mouse model, blood glucose levels were significantly higher in the T1DM group than those in the control group $(23.07 \pm 7.43$ vs. $6.40 \pm 1.25 \mathrm{mmol} / \mathrm{l}$, $\mathrm{P}<0.01)$, with a decrease in body weight $(20.32 \pm 4.76$ vs. $26.83 \pm 1.27 \mathrm{~g}, \mathrm{P}<0.05$ ) (Fig. 1A). During the wound healing process, the wound healing rate of the T1DM group was significantly lower than that of the controls $[0.07 \pm 0.05$ vs. $0.25 \pm 0.10$, $\mathrm{P}=0.009$ (day 3 ); $0.39 \pm 0.06$ vs. $0.65 \pm 0.04, \mathrm{P}=0.0001$ (day 7 ); $0.80 \pm 0.03$ vs. $0.89 \pm 0.02, \mathrm{P}=0.001$ (day 10); Fig. $1 \mathrm{~B}]$.

Vascular vessel formation is impaired in T1DM mice. CD31 is a specific marker widely used for vascular vessel identification (15). In the following experiments, CD31 protein levels were detected in the wounded skin of control and T1DM mice. During the wound healing process, the integral optical density of CD31 in the T1DM group was not statistically different from that in the control group on day $3(0.31 \pm 0.05$ vs. $0.32 \pm 0.02$, $\mathrm{P}=0.420$ ), while it was significantly lower than that in the control group on day $7(0.39 \pm 0.09$ vs. $0.57 \pm 0.10, \mathrm{P}=0.0001)$ and day 10 ( $0.62 \pm 0.18$ vs. $0.87 \pm 0.16, \mathrm{P}=0.0001)$ (Fig. $1 \mathrm{C})$. These results suggested that skin wound healing was impaired in the T1DM mice.

Akt/HIF-1 $\alpha$ and downstream signaling is attenuated in T1DM

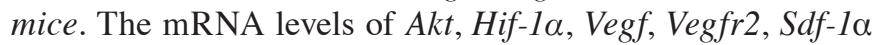
and $\mathrm{Cxcr} 4$ were detected in the wounded skin. As shown in Fig. 2, the mRNA levels of these genes generally reached a peak on days 3 and 7, while the overall mRNA levels in the T1DM group were significantly lower than those in the control group $(\mathrm{P}<0.05)$. Furthermore, the protein levels of HIF-1 $\alpha$, Akt, VEGF, VEGFR2, SDF-1 $\alpha$ and CXCR4 were detected using western blotting. The protein levels of HIF-1 $\alpha(\mathrm{P}=0.006), \mathrm{Akt}$ $(\mathrm{P}=0.025)$, VEGFR2 $(\mathrm{P}=0.003)$ and CXCR4 $(\mathrm{P}=0.032)$ in the T1DM group were significantly lower than those in the control group on day 0 , while on day 3 the protein levels of HIF-1 $\alpha$, Akt, VEGF, SDF-1 $\alpha$ and CXCR4 were significantly lower than those in the control group $(\mathrm{P}<0.01)$. The protein level of CXCR4 was significantly higher $(\mathrm{P}<0.05)$, while the overall protein levels of HIF-1 $\alpha$, Akt, VEGF, VEGFR2 and SDF- $1 \alpha$ were significantly lower in the T1DM group than those in the control group $(\mathrm{P}<0.01$, Fig. 3).

\section{Discussion}

Diabetes affects $\sim 170$ million individuals worldwide (1). By 2030, this number is expected to reach 438 million (16). Diabetic non-healing wounds, such as diabetic foot ulcer (DFU), are a major cause of morbidity in diabetic patients, often leading to infection, suffering and a poor quality of life. Despite existing protocols for standardized care, physiological defects associated with DFU can result in failure to heal, amputations or patient mortality (17). Stem cell-based autologous cell replacement therapy is considered to be a promising approach, yet remains in its infancy (18). Gene therapy is another potential approach for the treatment of diabetic wounds. The key issues of wound healing and tissue regeneration are how to restore the function of endothelial cells and promote tissue angiogenesis. In the present study, it was found that wound healing was impaired in T1DM mice, which was caused by decreased vascular vessel formation and deficient angiogenic signaling.

$\mathrm{PI} 3 \mathrm{~K} / \mathrm{Akt}$ signaling is required for VEGF expression via HIF-1 in response to growth factor stimulation $(19,20)$. 
A

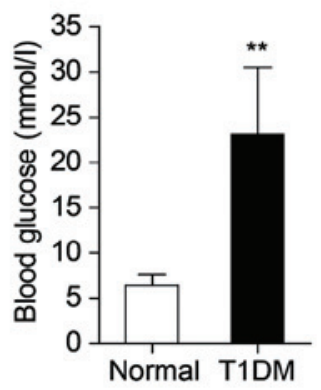

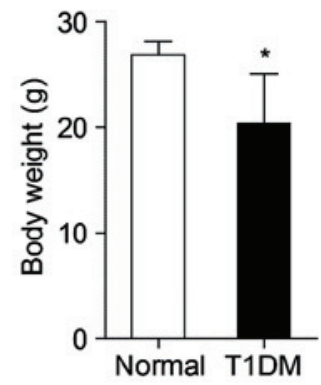

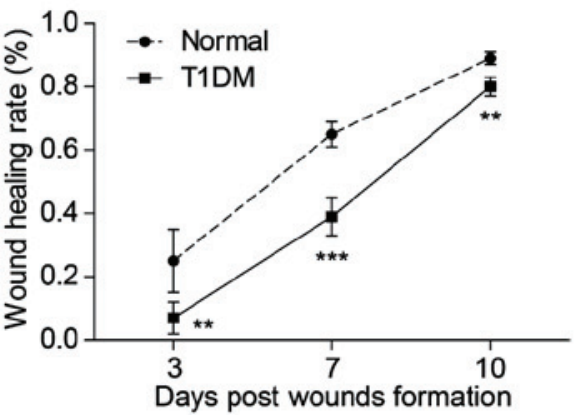

C
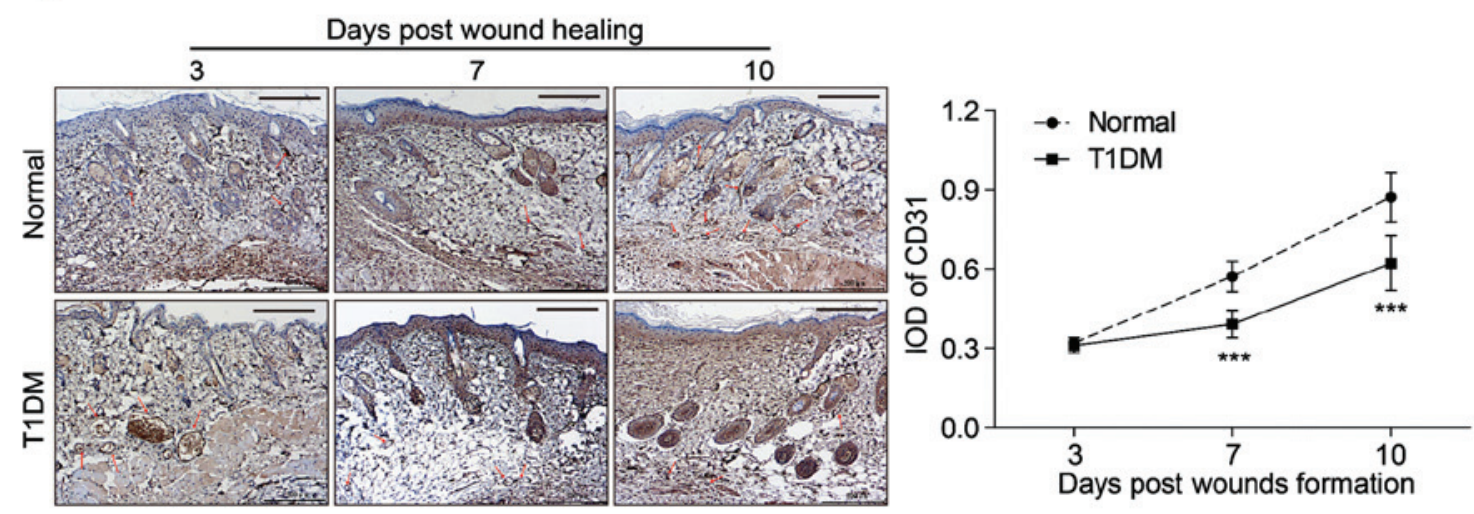

Figure 1. Wound healing rate and immunohistochemistry of CD31. BALB/c mice were randomly divided into control and diabetic groups (n=30 per group). Mice in the control and diabetic groups were injected with citric acid buffer solution or STZ for 7 days, respectively. (A) One month after STZ injection, blood glucose levels were measured and the average body weight was calculated. (B and C) Skin wounds were created one month after the establishment of the T1DM mouse model, and the wounded skin was collected on days $0(n=6), 3(n=8), 7(n=8)$ and $10(n=8)$ for the subsequent experiments. (B) Skin wound healing rates of the mice. (C) Representative images are shown of wounded skin stained with anti-CD31 antibody (left panel). The IOD was analyzed using Image-Pro Plus software (Media Cybernetics, Inc., Rockville, MD, USA) (right panel). Red arrows indicate the regions positive for CD31. Error bars represent the mean \pm standard deviation of $6-8$ mice. ${ }^{*} \mathrm{P}<0.05,{ }^{* *} \mathrm{P}<0.01$ and ${ }^{* * *} \mathrm{P}<0.001$ vs. the control group. CD31, cluster of differentiation 31 ; STZ, streptozotocin; T1DM, type 1 diabetes; IOD, integral optical density.

Following the formation of skin wounds, HIF-1 $\alpha$ is upregulated through hypoxia and PI3K/Akt signaling, leading to the upregulation of the levels of downstream angiogenesis-related factors, such as VEGF, SDF-1 $\alpha$ and CXCR4, the promotion of angiogenesis and the establishment of collateral circulation (21-23). VEGF is a major regulator of angiogenesis and induces the migration and proliferation of vascular vessel endothelial cells, promoting an increase in vasopermeability and angiogenesis and ameliorating wound blood supply. SDF-1 $\alpha / C X C R 4$ signaling can regulate the mobilization, homing, differentiation and amplification of multiple hemopoietic stem cells and circulating angiogenic cells (24). SDF- $1 \alpha$ participates in angiogenesis by stimulating endothelial cells to express VEGF and synergistically promoting the recruitment of endothelial progenitor cells to wounds (21). Suppression of SDF-1 $\alpha$ leads to decreased numbers of vascular vessels and granulation tissues and aggravation of the inflammatory response, severely impairing the normal wound healing process (22); therefore, Akt/HIF-1 $\alpha$ signaling and downstream pro-angiogenic factors play a critical role in the progression of diabetic wound healing.

In the present study, expression of the Akt/HIF- $1 \alpha$ axis and downstream genes was decreased in the T1DM mice prior to wound formation, which could explain the reduced angiogenesis and the delay in wound healing. High blood glucose levels in diabetic mice decrease HIF-1 activity and impair diabetic wound healing, which is closely correlated with decreased Akt, HIF-1 $\alpha$ and downstream signaling levels. A previous study has shown that high glucose concentrations lead to increased levels of hyperoxide, inducing the accumulation of pyruvaldehyde within the cells, and decreasing the protein levels and the transcriptional activity of HIF-1 $\alpha$ (25). The present experiments showed that Akt expression increased during wound formation, which stimulated the expression of HIF-1 $\alpha$ and downstream genes, with the expression reaching a peak on days 3 and 7. The expression of HIF-1 $\alpha$ and downstream genes increased on days 3 and 7 , which suggests that the expression of HIF- $1 \alpha$ and downstream genes is correlated with the proliferation period of wound healing. The increased expression of HIF-1 $\alpha$ and downstream genes on days 3 and 7 could be caused by the cells entering proliferation periods, which were characterized by granulation tissue formation in the wounds and gradual epithelialization, between 3 and 14 days after wound formation. Angiogenic endothelial cells and fibroblasts are important sources of VEGF and SDF-1 $\alpha$ (26). The hypoxic environment during the early stages of wound formation stimulates Akt/HIF-1 $\alpha$ and downstream signaling, while the expression of the HIF- $1 \alpha$ and downstream genes decreases following the improvement of the hypoxic environment. 
A

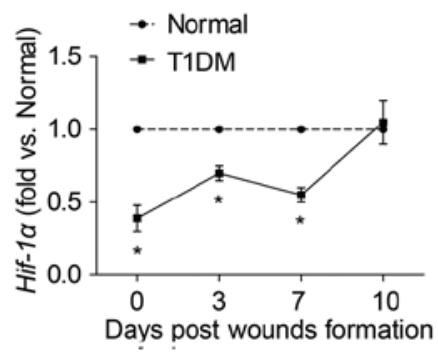

C

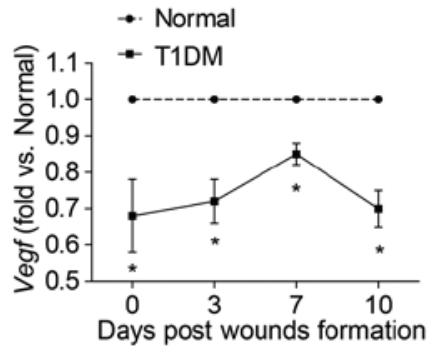

E

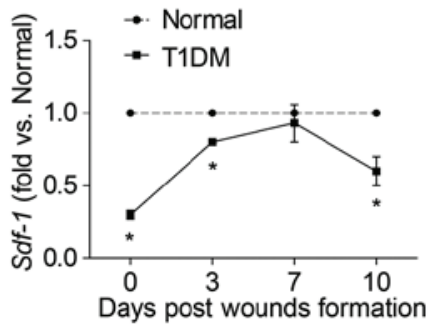

B

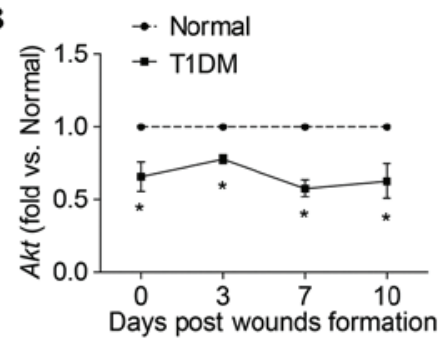

D

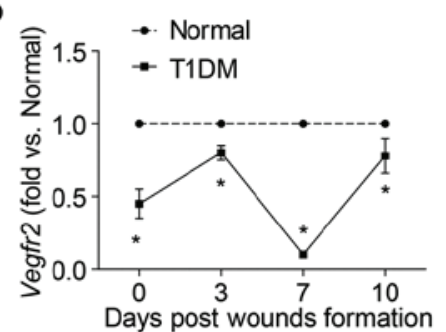

F

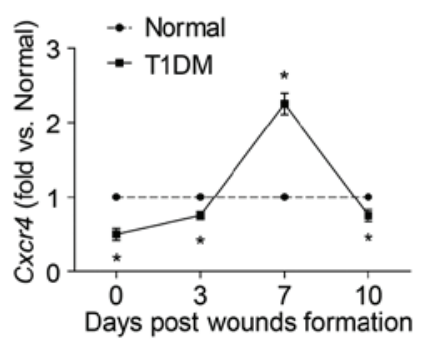

Figure 2. mRNA levels associated with Akt/HIF-1 $\alpha$ signaling in T1DM mice. BALB/c mice were randomly divided into control and diabetic groups (n=30 per group). Mice in the control and diabetic groups were respectively injected with citric acid buffer solution or streptozotocin for 7 days, respectively. Skin wounds were created one month after the establishment of the T1DM mouse model, and the wounded skin was collected on days $0(n=6), 3(n=8), 7(n=8)$ and $10(\mathrm{n}=8)$. Total RNA was extracted and the mRNA levels of (A) Hif-1 $\alpha$, (B) Akt, (C) Vegf, (D) Vegfr2, (E) Sdf-1 $\alpha$ and (F) Cxcr4 were detected using a reverse transcription-quantitative polymerase chain reaction and normalized with $\beta$-actin (internal control). Error bars are the mean \pm standard deviation for 6-8 mice. ${ }^{*} \mathrm{P}<0.05$ vs. control group. T1DM, type 1 diabetes; Hif-1 $\alpha$, hypoxia-inducible factor-1 $\alpha$; Vegf, vascular endothelial growth factor; Vegfr2, VEGF receptor 2; Sdf-1 $\alpha$, stromal cell-derived growth factor- $1 \alpha ; C x c r 4$, CXC chemokine receptor 4.
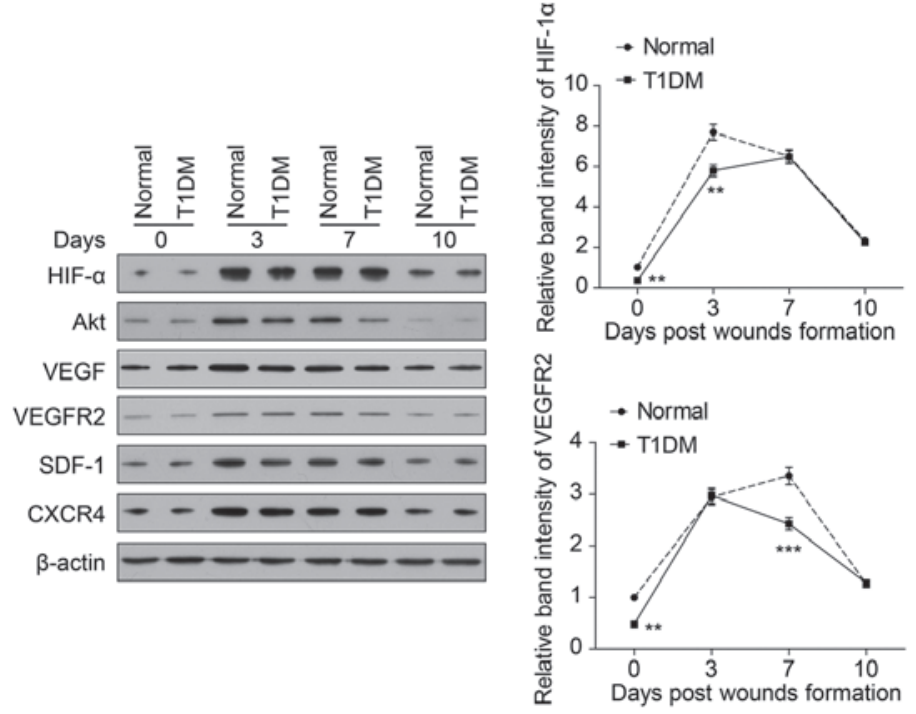
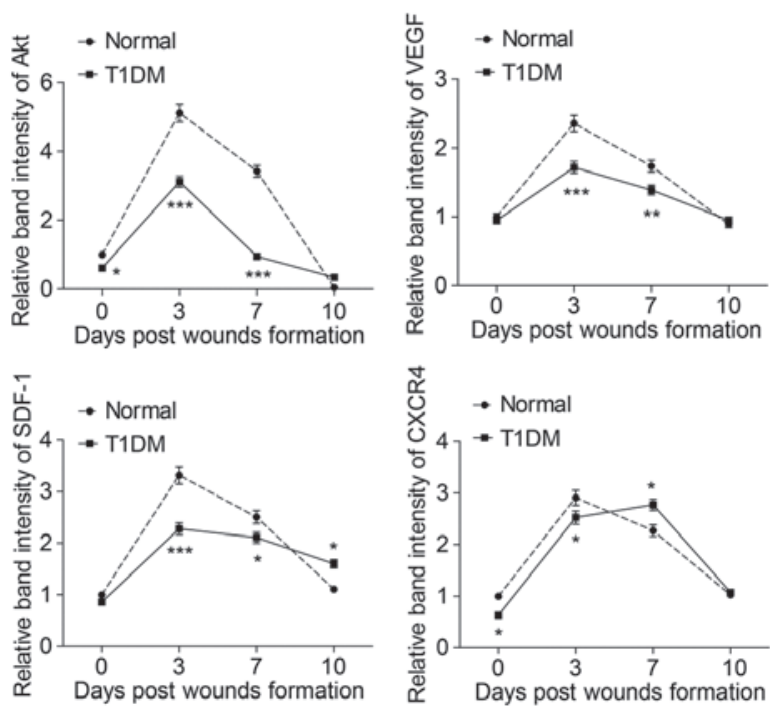

Figure 3. Protein levels of Akt/HIF-1 $\alpha$ signaling in T1DM mice. BALB/c mice were randomly divided into control and diabetic groups (n=30 per group). Mice in the control and diabetic groups were injected with citric acid buffer solution or streptozotocin for 7 days, respectively. Skin wounds were created one month after the establishment of the T1DM mouse model, and the wounded skin was collected on days $0(n=6), 3(n=8), 7(n=8)$ and $10(n=8)$. Total protein was extracted and the protein levels of HIF-1 $\alpha$, Akt, VEGF, VEGFR2, SDF-1 $\alpha$ and CXCR4 were detected with western blotting. Relative band intensity was analyzed with ImageJ software (National Institutes of Health, Bethesda, MD, USA) and normalized to $\beta$-actin (loading control) levels. Data are presented as the mean \pm standard deviation for $6-8$ mice. ${ }^{*} \mathrm{P}<0.05,{ }^{* *} \mathrm{P}<0.01$ and ${ }^{* * *} \mathrm{P}<0.001$ vs. control group. T1DM, type 1 diabetes; HIF- $1 \alpha$, hypoxia-inducible factor- $1 \alpha$; VEGF, vascular endothelial growth factor; VEGFR2, VEGF receptor 2; SDF-1 $\alpha$, stromal cell-derived growth factor-1 $\alpha$; CXCR4, CXC chemokine receptor 4. 
In the present study it was found that the mRNA and protein levels of VEGFR2 in the T1DM group were lower than those in the control group on day 7. The total levels of VEGFR2 in the present study were analyzed and the level of phosphorylated VEGFR2 was detected in our future studies to identify changes in activated VEGFR2; however, the role of VEGFR1 is unclear during skin wound healing, and could be analyzed in further studies.

During wound healing, the overall levels of Akt, HIF-1 $\alpha$, VEGF, VEGFR2, SDF-1 $\alpha$ and CXCR4 decreased in the T1DM mice, leading to a deficiency in angiogenesis and disorders of granulation tissue formation, which could explain the delayed wound healing in subjects with diabetes. The pathways affecting HIF- $1 \alpha$ activity and the importance of these pathways remain unknown. A constitutively active Hif- $1 \alpha$ transgene has been used as a therapeutic strategy in patients with no-option critical limb ischemia in a phase I dose-escalation study (27); therefore, gene therapy targeting Hif-l $\alpha$ or Hif-l $\alpha$ regulators may bring new hope for the clinical treatment of diabetic wounds.

\section{Acknowledgements}

This study was supported by a grant from the National Natural Science Foundation of China (no. 81101749). The authors would like to thank Medjaden Bioscience Ltd for assistance with the preparation of this manuscript.

\section{References}

1. Pedicino D, Liuzzo G, Trotta F, et al: Adaptive immunity, inflammation, and cardiovascular complications in type 1 and type 2 diabetes mellitus. J Diabetes Res 2013: 184258, 2013.

2. Siqueira MF, Li J, Chehab L, Desta T, Chino T, Krothpali N, et al: Impaired wound healing in mouse models of diabetes is mediated by TNF-alpha dysregulation and associated with enhanced activation of forkhead box O1 (FOXO1). Diabetologia 53: 378-388, 2010.

3. Dasu MR, Thangappan RK, Bourgette A, DiPietro LA, Isseroff R and Jialal I: TLR2 expression and signaling-dependent inflammation impair wound healing in diabetic mice. Lab Invest 90: 1628-1636, 2010.

4. Luo JD, Hu TP, Wang L, Chen MS, Liu SM and Chen AF: Sonic hedgehog improves delayed wound healing via enhancing cutaneous nitric oxide function in diabetes. Am J Physiol Endocrinol Metab 297: E525-E531, 2009.

5. Tie L, Li XJ, Wang X, Channon KM and Chen AF: Endothelium-specific GTP cyclohydrolase I overexpression accelerates refractory wound healing by suppressing oxidative stress in diabetes. Am J Physiol Endocrinol Metab 296: E1423-E1429, 2009.

6. Rai NK, Suryabhan, Ansari M, Kumar M, Shukla VK and Tripathi K: Effect of glycaemic control on apoptosis in diabetic wounds. J Wound Care 14: 277-281, 2005.

7. Darby IA, Bisucci T, Hewitson TD and MacLellan DG: Apoptosis is increased in a model of diabetes-impaired wound healing in genetically diabetic mice. Int J Biochem Cell Biol 29: 191-200, 1997.

8. Fitsialos G, Bourget I, Augier S, Ginouvès A, Rezzonico R, Odorisio T, et al: HIF1 transcription factor regulates laminin-332 expression and keratinocyte migration. J Cell Sci 121: 2992-3001, 2008.

9. Liu L, Marti GP, Wei X, Zhang X, Zhang H, Liu YV, et al: Age-dependent impairment of HIF-1alpha expression in diabetic mice: Correction with electroporation-facilitated gene therapy increases wound healing, angiogenesis and circulating angiogenic cells. J Cell Physiol 217: 319-327, 2008.
10. Janssen HL, Haustermans KM, Sprong D, Blommestijn G, Hofland I, Hoebers FJ, et al: HIF-1A, pimonidazole and iododeoxyuridine to estimate hypoxia and perfusion in human head-and-neck tumors. Int J Radiat Oncol Biol Phys 54: $1537-1549,2002$

11. Rey S, Lee K, Wang CJ, Gupta K, Chen S, McMillan A, et al: Synergistic effect of HIF-1 alpha gene therapy and HIF-1-activated bone marrow-derived angiogenic cells in a mouse model of limb ischemia. Proc Natl Acad Sci USA 106: 20399-20404, 2009.

12. Andrikopoulou E, Zhang X, Sebastian R, et al: Current insights into the role of HIF-1 in cutaneous wound healing. Curr Mol Med 11: 218-235, 2011.

13. Like AA and Rossini AA: Streptozotocin-induced pancreatic insulitis: New model of diabetes mellitus. Science 193: 415-417, 1976.

14. Srinivasan K, Viswanad B, Asrat L, Kaul CL and Ramarao P: Combination of high-fat diet-fed and low-dose streptozotocin-treated rat: A model for type 2 diabetes and pharmacological screening. Pharmacol Res 52: 313-320, 2005.

15. Schlereth SL, Neuser B, Caramoy A, Grajewski RS, Koch KR, Schrödl F, Cursiefen C and Heindl LM: Enrichment of lymphatic vessel endothelial hyaluronan receptor 1 (LYVE1)-positive macrophages around blood vessels in the normal human sclera. Invest Ophthalmol Vis Sci 55: 865-872, 2014.

16. Allain TJ, van Oosterhout JJ, Douglas GP, et al: Applying lessons learnt from the 'DOTS' tuberculosis model to monitoring and evaluating persons with diabetes mellitus in Blantyre, Malawi. Trop Med Int Health 16: 1077-1084, 2011

17. Richard JL, Sotto A and Lavigne JP: New insights in diabetic foot infection. World J Diabetes 2: 24-32, 2011.

18. Li S and Li Q: A promising approach to iPSC-based cell therapy for diabetic wound treatment: Direct lineage reprogramming. Mol Cell Endocrinol 393: 8-15, 2014.

19. Jiang BH, Jiang G, Zheng JZ, Lu Z, Hunter T and Vogt PK: Phosphatidylinositol 3-kinase signaling controls levels of hypoxia-inducible factor 1. Cell Growth Differ 12: 363-369, 2001.

20. Zhong H, Chiles K, Feldser D, Laughner E, Hanrahan C, Georgescu MM, Simons JW and Semenza GL: Modulation of hypoxia-inducible factor 1 alpha expression by the epidermal growth factor/phosphatidylinositol 3-kinase/PTEN/AKT/FRAP pathway in human prostate cancer cells: Implications for tumor angiogenesis and therapeutics. Cancer Res 60: 1541-1545, 2000.

21. Loh SA, Chang EI, Galvez MG, Thangarajah H, El-ftesi S, Vial IN, Lin DA and Gurtner GC: SDF-1 alpha expression during wound healing in the aged is HIF dependent. Plast Reconstr Surg 123 (2 Suppl): 65S-75S, 2009.

22. Bermudez DM, Xu J, Herdrich BJ, Radu A, Mitchell ME and Liechty KW: Inhibition of stromal cell-derived factor- $1 \alpha$ further impairs diabetic wound healing. J Vasc Surg 53: 774-784, 2011.

23. Thangarajah H, Yao D, Chang EI, Shi Y, Jazayeri L, Vial IN, et al: The molecular basis for impaired hypoxia-induced VEGF expression in diabetic tissues. Proc Natl Acad Sci USA 106: 13505-13510, 2009.

24. Kijowski J, Baj-Krzyworzeka M, Majka M, Reca R, Marquez LA, Christofidou-Solomidou M, Janowska-Wieczorek A and Ratajczak MZ: The SDF-1-CXCR4 axis stimulates VEGF secretion and activates integrins but does not affect proliferation and survival in lymphohematopoietic cells. Stem Cells 19: 453-466, 2001.

25. Thangarajah H, Vial IN, Grogan RH, Yao D, Shi Y, Januszyk M, et al: HIF-1 alpha dysfunction in diabetes. Cell Cycle 9: 75-79, 2010.

26. Ceradini DJ, Kulkarni AR, Callaghan MJ, Tepper OM, Bastidas N, Kleinman ME, et al: Progenitor cell trafficking is regulated by hypoxic gradients through HIF-1 induction of SDF-1. Nat Med 10: 858-864, 2004.

27. Rajagopalan S, Olin J, Deitcher S, Pieczek A, Laird J, Grossman PM, et al: Use of a constitutively active hypoxia-inducible factor- 1 alpha transgene as a therapeutic strategy in no-option critical limb ischemia patients: Phase I dose-escalation experience. Circulation 115: 1234-1243, 2007. 